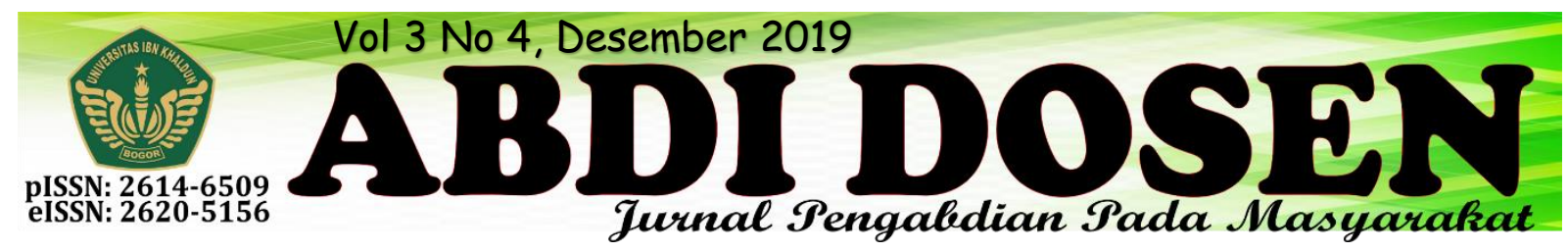

\title{
PEMANFAATKAN POTENSI LINGKUNGAN, MELALUI DAUR ULANG SAMPAH BOTOL PLASTIK MENJADI BAHAN BAKAR BIOSOLAR DI KAMPUNG CIPAKEL DESA LEUWEUNG KOLOT
}

\author{
Badruddin Hsubky ${ }^{1}$, Fajar Suaeb, Adisti Fitri Indriyani ${ }^{2}$ \\ badruddin@uika-bogor.ac.id \\ Fakultas Agama Islam Universitas Ibn Khaldun ${ }^{1}$, Mahasiswa KKN Kelompok 32 Tahun $2018^{2}$
}

\begin{abstract}
ABSTRAK
Sampah plastik merupakan permasalahan lingkungan hidup yang dihadapi oleh masyarakat indonesia dan dunia. Sampah plastik adalah salah satu sumber pencemaran lingkungan hidup. Plastik merupakan produk serbaguna, ringan, fleksibel, tahan kelemapan, kuat, dan relatif murah. Pemnafaatan sampah plastik juga dapat dijadikan suatu produk kreatiitas. Seperti mendaur ulang plastik menjadi tas, hiasan ruangan, baju, dan seni-seni lainnya. Penanganan sampah plastik yang sudah banyak diterapkan adalah dengan Konsep 3R (Reuse, Reduce dan Recycle) dan alternatif lain yang sudah banyak diteliti adalah daur ulang sampah plastik dijadikan Bahan Bakar Biosolar Murni. Biosolar merupakan bahan bakar mesin disel yang terbuat dari bahan terbarukan atau secara khusus merupakan bahan bakar yang terdiri atas ester alkil dari asam-asam lemak yang dibuat dari minyak nabati, minyak hewani atau dari minyak goreng bekas/daur ulang melalui proses tertentu.
\end{abstract}

Kata Kunci : Sampah Plastik, Pemanfaatan, Daur ulang, Bahan bakar, Biosolar.

\section{PENDAHULUAN}

Plastik merupakan senyawa polimer yang unsur penyusun utamanya adalah Karbon dan Hidrogen. Untuk membuat plastik, salah satu bahan baku yang sering digunakan adalah Naphta, yaitu bahan yang dihasilkan dari penyulingan minyak bumi atau gas alam. Sebagai gambaran, untuk membuat $1 \mathrm{~kg}$ plastik memerlukan $1,75 \mathrm{~kg}$ minyak bumi, untuk memenuhi kebutuhan bahan bakunya maupun kebutuhan energi prosesnya. Bahan kemasan plastik dibuat melalui proses polimerisasi. Selain bahan dasar monomer, plastik juga mengandung bahan aditif yang diperlukan untuk memperbaiki sifat fisiko kimia plastik tersebut, dan disebut komponen non plastik. Kemasan plastik memiliki beberapa keunggulan karena sifatnya yang kuat, tetapi ringan, inert, tidak karatan dan bersifat termoplastik (heat seal) serta dapat diberi warna .

Sifat plastik dibagi menjadi dua yaitu Thermoplastic dan Thermosetting. Thermoplastic merupakan bahan plastik yang jika dipanaskan sampai temperatur tertentu, akan mencair dan dapat dibentuk kembali menjadi bentuk yang diinginkan. Sedangkan Thermosetting yaitu plastik yang jika telah dibuat dalam bentuk padat, tidak dapat dicairkan kembali dengan cara dipanaskan.

Plastik merupakan polimer sintesis yang bersifat sulit terurai di alam. Untuk dapat terurai secara sempurna dibutuhkan waktu hampir ratusan tahun. Bila dibandingkan antara penggunaan plastik 
yang terus meningkat terhadap waktu yang dibutuhkan untuk terurai tentu sudah dapat dibayangkan bagaimana dampak penumpukan limbah plastik pada lingkungan. Kerusakan lingkungan akibat limbah plastik tidak lepas dari tanggung jawab kita sebagai manusia yang diamanahkan sebagai khalifah di bumi Allah yang mana seharusnya kita manjaga dan melestarikan bukan malah merusaknya. Hal ini sesuai dengan firman Allah SWT dalam Q.S. Ar-Rum ayat 4142.

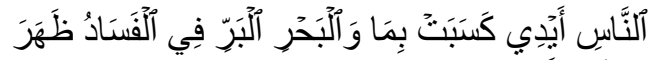

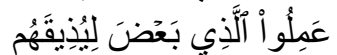

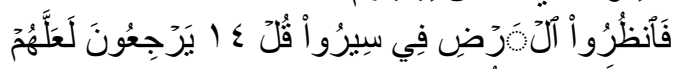

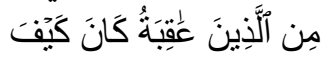

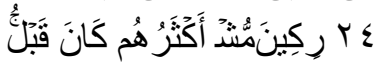

Artinya : "Telah tampak kerusakan di darat dan di laut disebabkan karena perbuatan tangan manusia; Allah menghendaki agar mereka merasakan sebagian dari (akibat) perbuatan mereka, agar mereka kembali (kejalan yang benar). Katakanlah (Muhammad), "Bepergianlah di bumi lalu lihatlah bagaimana kesudahan orangorang dahulu. Kebanyakan dari mereka adalah orang-orang yang mempersekutukan (Allah)."

\section{Kondisi Wilayah}

Letak Geografis Desa Leuweung Kolot luas wilayahnya 189,900,000 Ha, Desa Leuweung Kolot berada di Kecamatan Cibungbulang, dimana dalam satu desa terdapat 5 Rukun warga (RW) dan dalam satu Rukun Warga terdapat 5 Rukun Tetangga. Di Desa Leuweung Kolot terdapat kampung Cipakel, Curug, Bubulak, Cikonjen. Ada pun batas-batas wilayahnya sebagai berikut:

\begin{tabular}{|l|l|}
\hline Batas & Desa \\
\hline Sebelah Utara & Ciaruten Ilir \\
\hline Sebelah Selatan & Girimulya \\
\hline Sebelah Timur & $\begin{array}{l}\text { Cibadak, } \\
\text { Kec Ciampea }\end{array}$ \\
\hline Sebelah Barat & Cimanggu I \\
\hline
\end{tabular}

Jarak dari Desa Leuweung Kolot ke ibu kota Kecamatan Cibungbulang $8 \mathrm{Km}$, jarak ke ibu kota Kabupaten Bogor $37 \mathrm{Km}$, jarak ke ibu kota Provinsi di Bandung 120 $\mathrm{Km}$ dan jarak ke ibu kota Negara di Jakarta $60 \mathrm{Km}$.

Topografi Desa Puraseda merupakan desa yang berada didaerah dataran rendah, dengan ketinggian 600-700 meter diatas permukaan laut (mdpl). Sebagian besar wilayah desa adalah lahan pesawahan dan pemukiman dan kemiringanperbukitan antara $20^{\circ}-45^{\circ}$. Suhu rata-rata harian mencapai $30-42^{\circ} \mathrm{C}$.

Hidrologi Dan Klimatologi, Sumber air yang ada di Desa Leuweung Kolot meliputi air permukaan dan air tanah. Air permukaan berupa sungai. Sesuai dengan kebijakan penyediaan air baku untuk irigasi, maka di Desa Leuweung Kolot mendapat pasokan pelayanan irigasi berasal dari PDAM, Sedangkan untuk kebutuhan rumah tangga, masyarakat sebagian menggunaan air bersih dari pembuatan sumur pribadi.

Luas dan sebaran penggunaan lahan pada umumnya lahan yang berada atau terdapat di Desa Leuweung Kolot digunakan secara produktif, karena merupakan lahan yang subur terutama untuk lahan pertanian, jadi hanya sebagian kecil saja yang tidak dimanfaatkan oleh warga, hal ini pula menunjukan bahwa kawasan Desa Leuweung adalah daerah yang memiliki sumber daya alam yang memadai. 


\section{METODOLOGI}

partisipasi masyarakat sudah lebih dari satu dasawarsa menjadi kata kunci dalam bahasa masyarakat pembangunan. Namun dalam kenyataannya program pembangunan dan pengembangan msyarakat masih juga dilakukan dengan cara lama yang mengabaikan konsep partisipasi. Program pembangunan masih saja diturunkan dari atas dan masyarakat tinggal melaksanakannya tanpa adanya keterlibatan langsung masyarakat yang menjadi sasaran program tersebut. Kalaupun ada penjajagan terhadap kebutuhan pembangunan, itupun dilakukan dengan cara survai, studi atau penelitian formal yang dilakukan oleh lembaga penelitian atau perguruan tinggi yang karena beberapa asumsi yang kurang tepat, maka program tidak menyentuh kebutuhan yang sesungguhnya. Dengan sendirinya dukungan masyarakat terhadap program tersebut menjadi pura-pura, demikian pula partisipasinya. yang berpengaruh terhadap keberlanjutan dari program tersebut.

Alasan-alasan yang demikian melahirkan beragam pemikiran tentang pendekatan pengembangan program yang lebih partisipatif. Istilah-istilah partisipasi masyarakat, perencanaan dari bawah (bottom-up planning), penyadaran, pendekatan yang berpusat pada petani (farmer centered approach), dll menjadi kosa kata para aktivis pembangunan, baik pemerintah maupun swasta, walaupun kenyataannya belum mencerminkan arti kata tersebut. Program-program yang ada masih saja tetap diturunkan dari atas (topdown approach ), direncanakan dari meja kantor, sementara masyarakat diperkenankan berpartisipasi dalam pelaksanaan fisik di lapangan, sehingga tingkatan partisipasinya masih layak disebut sebagai mobilisasi.

Demikian mendorong untuk diperkenalkannya salah satu metode dan teknik yang dikenal dengan Participatory Rural Appraisal(PRA), karena dipandang telah memiliki teknik-teknik yang dijabarkan cukup operasional dengan konsep bahwa keterlibatan masyarakat sangat diperlukan dalam seluruh kegiatan. Pendekatan PRA memang bercita-cita menjadikan masyarakat menjadi peneliti, perencana, dan pelaksana pembangunan dan bukan sekedar obyek pembangunan. Tekanan aspek penelitian bukan pada validitas data yang diperoleh, namun pada nilai praktis untuk pengembangan program itu sendiri. Penerapan pendekatan dan teknik PRA dapat memberi peluang yang lebih besar dan lebih terarah untuk melibatkan masyarakat. Selain itu melalui pendekatan PRA akan dapat dicapai kesesuaian dan ketepatangunaan program dengan kebutuhan masyarakat sehingga keberlanjutan (sustainability ) program dapat terjamin.

PRA adalah suatu metode pendekatan untuk mempelajari kondisi dan kehidupan pedesaan dari, dengan, dan oleh masyarakat desa. Atau dengan kata lain dapat disebut sebagai kelompok metode pendekatan yang memungkinkan masyarakat desa untuk saling berbagi, meningkatkan, dan menganalisis pengetahuan mereka tentang kondisi dan kehidupan desa, membuat rencana dan bertindak (Chambers, 1995). 


\section{REALISASI PROGRAM}

Pelaksanaan program kerja KKN 61 selama 1 bulan terhitung mulai tanggal 07 Agustus - 05 September 2018 di Kp. Cipakel RT/RW 05-04 Des. Leuweung Kolot Kec. Cibungbulang Kab. Bogor adalah sebagai berikut:

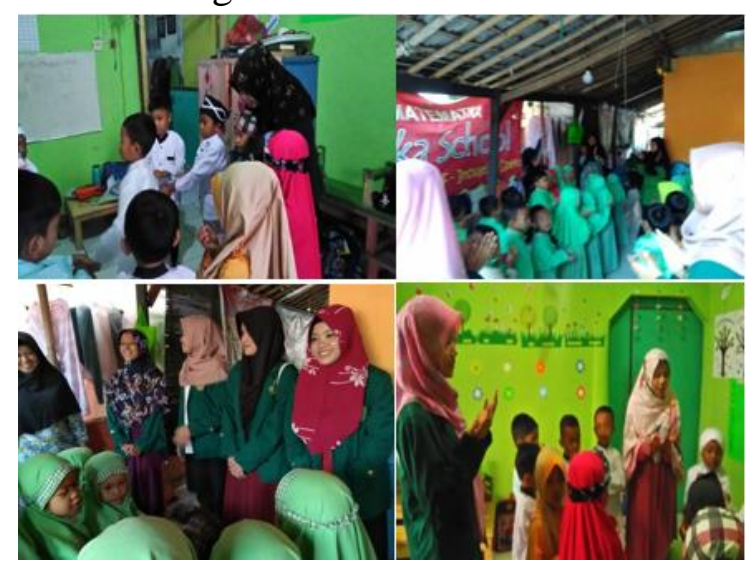

Kegiatan mengajar di Paud ArRobbaniyah

Mengajar pada dasarnya merupakan suatu usaha untuk menciptakan kondisi atau sistem lingkungan yang mendukung dan memungkinkan untuk berlangsungnya proses belajar. Program ini dilaksanakan oleh bidang pendidikan setiap hari senin sampai jum'at pukul $07.00 \mathrm{~s} / \mathrm{d}$ selesai yang bertempatkan di Paud Ar-Robaniyah Kampung Cipakel Rw 04.
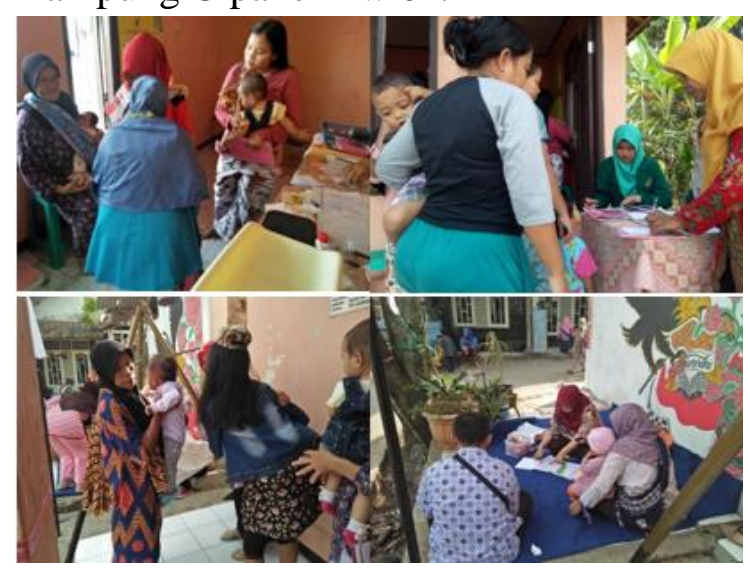

\section{Pemantauan dan Pembaharuan}

\section{Posyandu Bayi dan Balita}

Pos Pelayanan Keluarga Berencana Kesehatan Terpadu (Posyandu) adalah kegiatan kesehatan dasar yang diselenggarakan dari, oleh dan untuk masyarakat yang dibantu oleh petugas kesehatan. Posyandu merupakan salah satu Upaya Kesehatan Bersumberdaya Masyarakat (UKBM). Jadi, Posyandu merupakan kegiatan swadaya dari masyarakat di bidang kesehatan dengan penanggung jawab kepala desa. Kegiatan ini dilaksanakan pada tanggal 10 Agustus 2018 yang dimulai pada pukul $09.00 \mathrm{~s} / \mathrm{d}$ selesai.

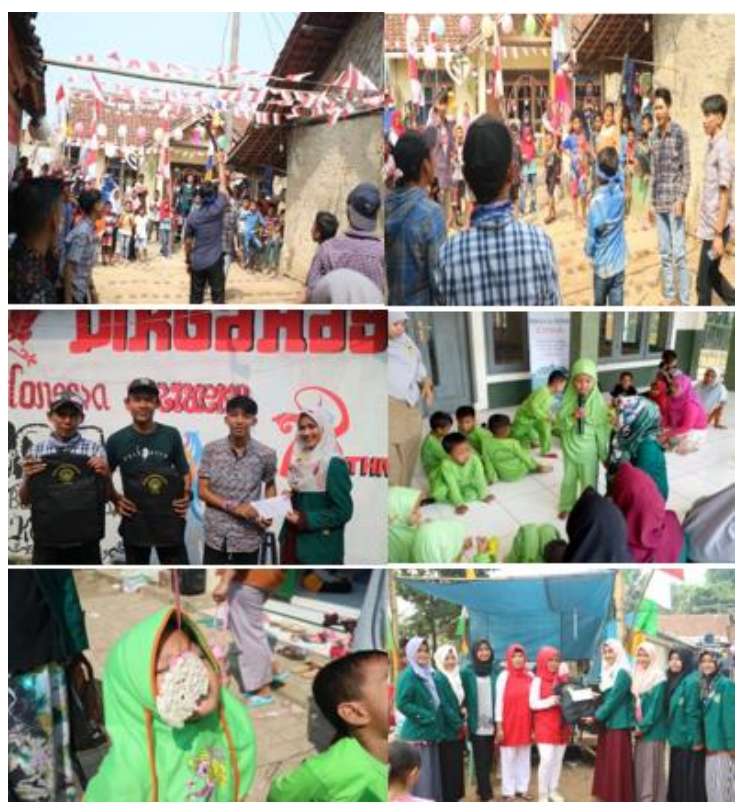

Kegiatan 17 Agustus di Kampung Cipakel dan di Paud Ar-Robbaniyah

Pelaksanaan ini dilakukan pada hari minggu 17 Agutus 2018 pada pukul 08.00 s/d di Kampung Cipakel dan 20 Agustus 2018 pada pukul 08.00 s/d selesai di Paud Ar-Robbaniyah. Maksud dari pelaksanaan 17 agustus ini adalah untuk memeriahkan hari ulang tahun Indonesia dengan melakukan beberapa kegiatan perlombaan yang di ikuti oleh warga kampung Cipakel dan anak - anak Paud Ar - Robaniyyah. 


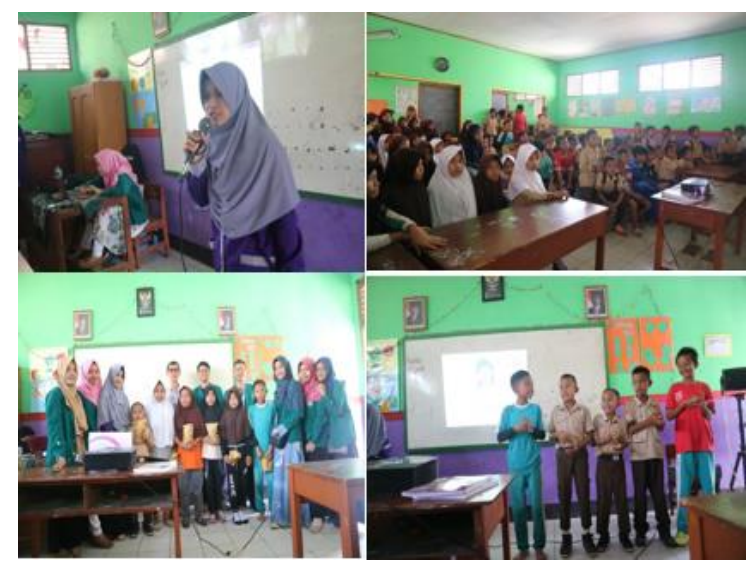

Penyuluhan Kesehatan tentang PHBS (Perilaku Hidup Bersih dan Sehat) mengenai CTPS (Cuci Tangan Pakai Sabun)

Mencuci tangan adalah proses yang secara mekanis melepaskan kotoran dan debris dari kulit tangan dengan menggunakan sabun biasa dan air (DEPKES, 2007). Penyuluhan ini bermaksud untuk memberikan komunikasi informasi dan edukasi (KIE) agar Siswa siswi kelas 4, 5 dan 6 SDN 05 Leuweung Kolot dapat membudayakan perilaku mencuci tangan dengan benar untuk meningkatkan perilaku hidup bersih dan sehat sebagai upaya awal peningkatan kesehatan. Kegiatan ini diadakan pada hari sabtu tanggal 25 agustus 2018 pukul 10.00 s/d selesai.

Penyuluhan Gemar Menabung dan Kreasi Celengan

Kami melaksanakan penyuluhan gemar menabung pada hari Sabtu 1 September 2018 pukul 10.00 s/d selesai dengan memberikan pemaparan kepada siswa-siswi kelas 4, 5 dan 6 di SDN 05 Leuweung Kolot agar bisa menabung atau menyisihkan uangnya dengan menabung, memberikan penjelasan tentang seberapa penting menanamkan budaya menabung sejak dini dan memberikan pelatihan cara membuat celengan dari bahan daur ulang seperti botol bekas. Kami pun memberikan hadiah sebuah celengan kepada semua siswa siswi bagi yang bisa menjawab pertanyaan seputar materi tentang menabung yang sudah di sampaikan oleh kami. Selain itu, kami mengadakan kreasi membuat celengan bagi dengan anak anak RT $05 \mathrm{Kp}$. Cipakel guna untuk meningkatkan kreatifitas dalam membuat tabungan.

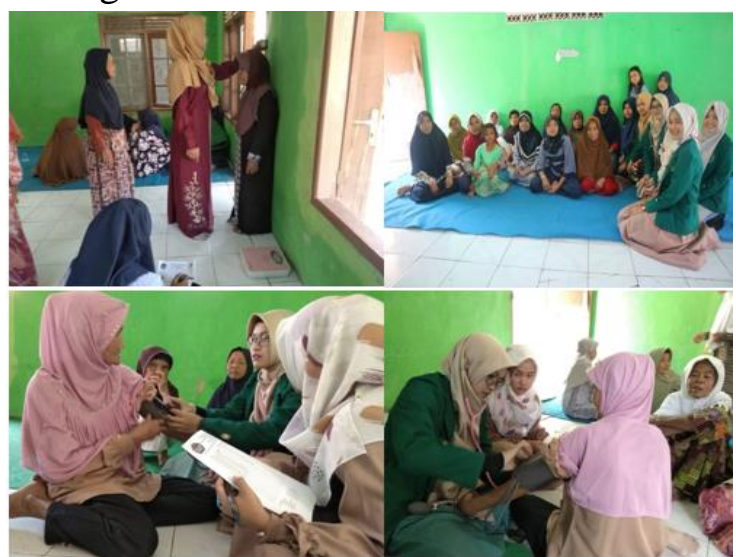

Cek Kesehatan Gratis (Pemeriksaan Tekanan darah dan pengukuran Indeks Massa Tubuh)

Program cek kesehatan gratis ini dilakukan kepada seluruh warga Rt $05 \mathrm{Rw}$ 04 di kampung Cipakel Desa Leuweung Kolot. Kegiatan ini dilaksanakan setelah pengajian Majelis Ta'lim Raudatul Jannah pada tanggal 03 september 2018. Program ini diadakan guna skrining tekanan darah dan indeks massa tubuh pada masyarakat Desa leuweung kolot Rt 05 Rw 04 dan di harapkan dapat menjadi acuan yang digunakan dalam penentuan kualitas kesehatan.

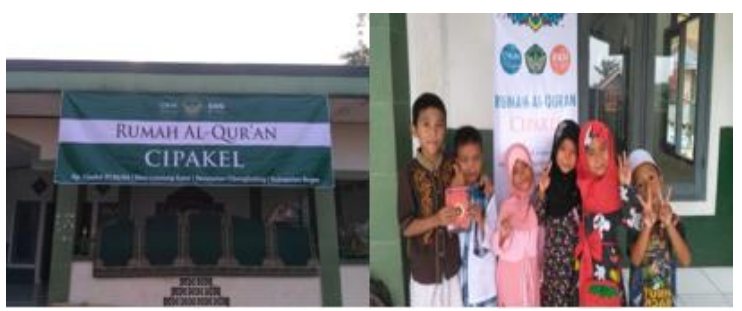

\section{Kegiatan Rumah Qur'an}

TPA (Taman Pengajian Anak-anak) merupakan wadah yang berfungsi untuk menjembatani dan memfasilitasi anak-anak dalam mempelajari iqro atau Al-Quran 
baik dalam Tahsin maupun Tahfiz. Program ini dilaksanakan setiap hari seninjumat pukul $15.30 \mathrm{~s} / \mathrm{d}$ selesai bertempatkan di Masjid Rajih Al-Qhatany Kampung Cipakel Rw 04.

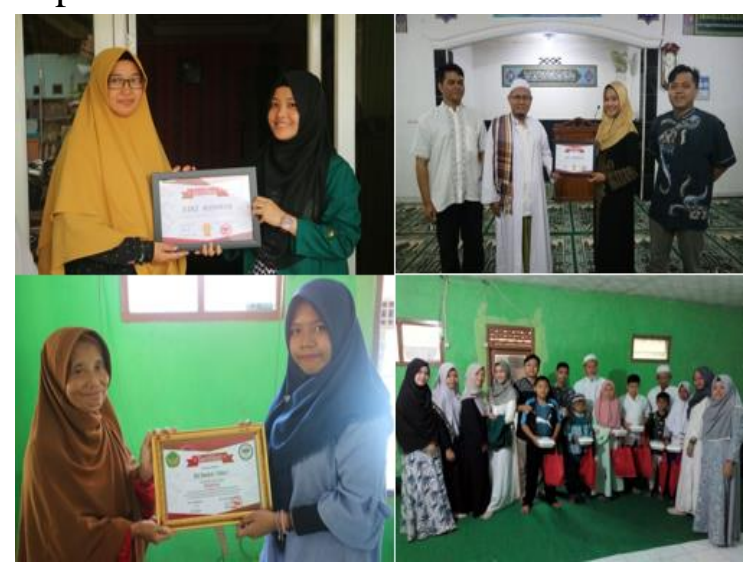

\section{Kegiatan Penyuluhan}

Pelaksanaan program penyuluhan diantaranya ada tiga penyuluhan yaitu (1) Penyuluhan mengenai Kekerasan Terhadap Anak yang di adakan di pengajian Liqo pada tanggal 29 agustus 2018 pukul 10.00 s/d selesai (2) Penyuluhan mengenai Kekerasan di Kalangan Remaja di Masjid Rajih Al-Qhatany tanggal 29 agustus 2018 pukul 19.00 s/d selesai dan (3) Penyuluhan mengenai Pentingnya Pendidikan Anak Usia Dini di Majelis Ta'lim Rodatul Jannah tanggal 03 september 2018 pukul $09.00 \mathrm{~s} / \mathrm{d}$ selesai. Maksud dari pelaksanaan penyuluhan ini guna untuk menambah pengetahuan dengan cara mempengaruhi prilaku masyarakat baik itu secara individu atau pun kelompok dengan menyampaian pesan

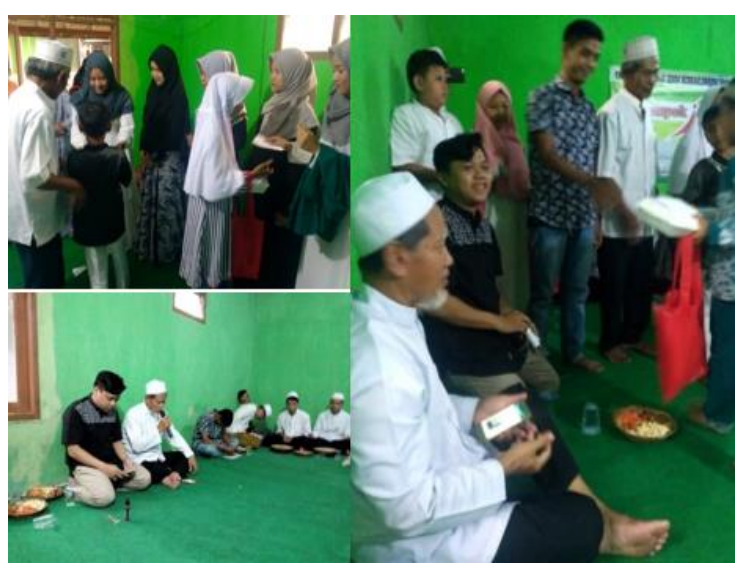

\section{Kegiatan Santunan Anak Yatim}

Pelaksanaan di lakukan pada hari selasa 04 September 2018 pukul $16.30 \mathrm{~s} / \mathrm{d}$ 18.00. Maksud dari pelaksanaan santunan anak yatim ini adalah Menjadikan Kegiatan santunan ini sebagai titik tolak langkah kedepan untuk menumbuh kembangkan dan memasyarakatkan nilainilai sosial kemasyarakatan. Dengan tujuan Sebagai wujud keperdulian terhadap sesama khususnya anak-anak yatim piatu serta kaum duafa yang membutuhkan kasih sayang melalui bersilaturahim khususnya bagi masyarakat kampung Cipakel Rw 04 Desa Leuweung Kolot.

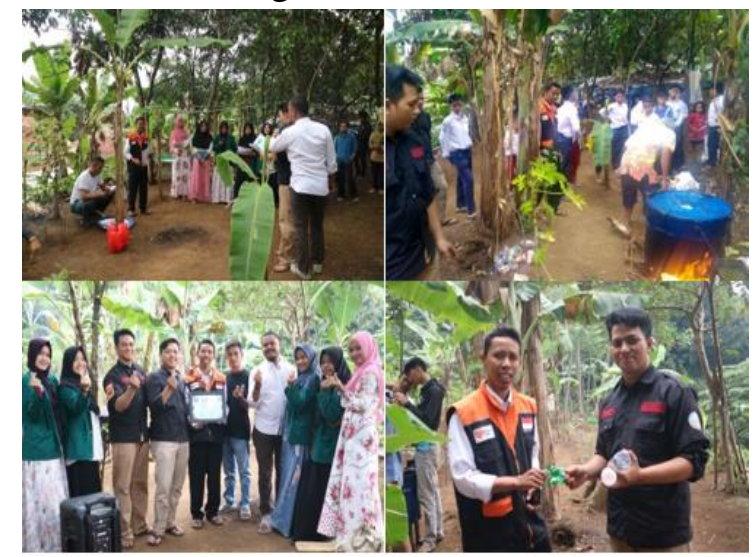

Kegiatan Penyuluhan Biosolar

Diberikannya penyuluhan terhadap warga mengenai sampah plastik yang akan dijadikan Biosolar sehingga warga dapat memilah sampah dan dapat di buat menjadi bahan bakar biosolar yang dapat membantu mesin traktor atau alat pertanian lainnya. Pelaksanaan penyuluhan ini dilakukan 
pada hari rabu 05 September 2018 pada pukul $02.00 \mathrm{~s} / \mathrm{d}$ selesai.

\section{KESIMPULAN}

KKN merupakan salah satu mata kuliah wajib bagi mahasiswa untuk mengabdikan diri kepada masyarakat. Hal ini ditujukan untuk melatih mahasiswa dalam hidup bermasyarakat serta untuk memberdayakan masyarakat dengan cara meningkatkan kreativitas dan kemampuan, membantu masyarakat melakukan fungsi keluarga melalui program-program .

Dalam bidang Pendidikan, Kp.Cipakel Rt 05 Rw 04 tergolong belum cukup baik dalam hal perhatian terhadap pentingnya pendidikan, khususnya pendidikan untuk anak usia dini. Hal tersebut terlihat dari kurangnya kesadaran orang tua yang harus memiliki semangat tinggi menyekolahkan anaknya. Pemberian bimbingan belajar atau jam tambahan belajar untuk siswa SD dan SMP merupakan salah satu hal penting yang harus diperhatikan, karena kemampuan anak dengan tingkat pendidikan yang ditempuh sesuai dengan yang diharapkan.

Dalam bidang Kesehatan di Kp. Cipakel Rt 05 Rw 04 dengan adanya puskesmas cibungbulang dan dari segi kegiatan Posyandu, sudah tergolong baik karena intensitas kegiatan bersifat rutin dengan tim penggerak kader dan petugas

puskesmas yang aktif untuk memantau ke setiap posyandu.

Permasalahan Lingkungan di Kp Cipakel Rt 05 Rw 04. Masih kurang memadai karena tidak adanya tempat pembuangan sampah, alat pengangkut sampah dari dinas pun jarang dan terkadang masa pengangkutan harus menunggu berbulan-bulan. Sebagian masyarakat Kp.Cipakel Rw 04 terkadang kurang begitu peduli dengan kondisi lingkungannya, khususnyadi daerah lokasi KKN kami, sehingga kami membuat program pengadaan alat daur ulang sampah plastik menjadi biosolar yang secara sukarela diberikan untuk warga Kp. Cipakel sebagai bahan percontohan untuk masyarakat Kp. Cigoong. Hal tersebut bertujuan untuk menumbuhkan kesadaran masyarakat akan pentingnya kebersihan lingkungan dengan tidak membuang sampah sembarangan.

Bidang Ekonomi di Kp Cipakel Rt 05 Rw 04 menunjang dengan adanya menabung sejak dini agar anak-anak terbiasa menabung atau menyisihkan uangnya dengan menabung, agar bisa menanamkan budaya menabung sejak dini. 


\section{SARAN}

Dalam Bidang Pendidikan perlunya perhatian lebih dari orang tua terhadap kemajuan pendidikan anak. Adakan perpustakaan keliling agar motivasi anak untuk belajar meningkat. Adakan penyuluhan secara berkala baik itu pada peserta didik dan orang tua untuk meningkatkan motivasi pendidikan. Adakan kursuskomputer dan bahasaasing. Adakan kelompok belajar kecil bagi peserta didik.

Dalam bidang kesehatan dan lingkungan, berdayakan kembali keluarga

\section{REFERENSI}

Buku Pedoman KKN UIKA

Purwaningrum, Pramiati, Jakarta 2016, Upaya Mengurangi Timbulan Sampah Plastik di Lingkungan

https://lingkungahidup.co/sampah-plastikindonesia-dunia/ sadar kebersihan dan kesehatan. Adakan pembinaan PKK secara berkala agar lebih professional meningkatkan kesehatan. Melakukan pengelolaan sampah secara terstruktur, adakan tempat pembuangan tempat sampah akhir dan adakan kerja bakti rutin.

Dalam bidang kewirausahaan adakan pelatihan untuk warga dalam mengolah sumber daya yang ada secara rutin. Tumbuhkan jiwa kewirausahaan pada setiap warga dan adakan penyuluhan pemanfaatan limbah rumah tangga.

www.jurnal.arraniry.com/index.php/elkawnie

Elkawnie: Journal of Islamic Science and Technology Vol. 1, No.1, Juni 2015 atau www.jurnal.arraniry.com/index.php/elkawnie

Data Leuweung Kolot dan Posyandu Desa Leuweng Kolot 